\title{
An Examination of High School Personnel Prepare Students with Disabilities to Self-advocate for Favorable Post High School Outcomes.
}

\author{
Leigh Wittmeyer-Gruber, EdD \\ Director of Special Education, \\ Fort Osage Public Schools. Independence, MO, USA \\ Barbara N. Martin, EdD \\ School of Professional Education and Leadership, \\ University of Central Missouri. Warrensburg, Missouri, USA
}

\begin{abstract}
This paper explored the perceptions of special education staff and college students with disabilities about self-advocacy instruction provided in high schools. Data revealed differing perceptions about the level of self-advocacy instruction that students with disabilities receive while in high school between teachers and students. The implications for this research and practice include opportunities that high schools must have to teach students with disabilities self-advocacy skills to prepare them for post-school success.
\end{abstract}

Keywords: students with disabilities, transition planning, self-advocacy,

\section{INTRODUCTION}

Although there have been mandated transition services for students with disabilities for some time (Hetherington et al., 2010), their post-school outcomes lag behind those of students without disabilities. Within two years of graduating from high school, $10 \%$ of students with disabilities entered a two-year college and fewer than 6\% entered a four-year institution (Wagner et al., 2012). Additionally, according to Gregg (2009), once students with disabilities enter a postsecondary institution, their graduation rate continues to be lower than that of the general population with $28 \%$ of the students with disabilities graduating from college, which is approximately half of the graduation rate for students without disabilities. Not only are students with disabilities not graduating from college at the same rate as those without disabilities, but those that do are also taking longer to graduate. Within six years of completing high school, only $29.4 \%$ of students with disabilities had completed college, while $42.2 \%$ of students without disabilities had graduated (Sanford et al., 2011).

Due to the dismal statistics about post-school outcomes for students with disabilities (Gregg, 2009), it is important to plan appropriately to increase their chances for success in college and students to become an integral part of the transition planning process (Williams-Diehm et al., 2014). This transition plan is required to address a variety of components including the student's needs, preferences, and interests (Morningstar \& Liss, 2008). In addition to these components, transition planning should also include instruction in self-advocacy skills. Selfadvocacy means having the support and knowledge to direct one's own life, including articulating strengths, interests, and preferences, in a way that is personally meaningful (Carter, Trainor, Owens, Sweden \& Sun, 2010; Karvonen, Test, Wood, Browder, \& Algozzine, 2004). 
Since students with learning disabilities are their advocates on college campuses, it is imperative that students with disabilities be able to disclose their disability as well as practice self-advocacy skills (Gil, 2007; Foley, 2006; Schreiner, 2007). The ability of students to selfadvocate has shown to lead to better post-school outcomes and greater financial independence (Wehmeyer \& Palmer, 2003).

Specifically, this study focused on the instruction and practice of self-advocacy skills while students were in high school. In this inquiry, self-advocacy referred to the support and knowledge to direct one's own life, including articulating strengths, interests, and preferences, in a way that is personally meaningful (Carter et al., 2010). Components of self-advocacy include knowledge of self, knowledge of rights, communication, and leadership (Test, Fowler, Wood, Brewer, \& Eddy, 2005). Therefore, the following questions guided this inquiry: How do high school special education teachers implement self-advocacy skills? Moreover, what are the perceptions of college students with learning disabilities regarding their instruction in the selfadvocacy skills?

\section{Transition planning}

\section{LITERATURE REVIEW}

The Individuals with Disabilities in Education Act Amendments of 1990 added a requirement that transition planning for students with disabilities must be in the student's IEP (Hurwitz, 2008). The transition plan is required to address a variety of components including the student's needs, preferences, and interests (Morningstar \& Liss, 2008). A well-developed transition plan will address the wide variety of needs that a student is going to face, including self-advocacy skills, educational needs, and other demands from the university (Smith et al., 2002).

Williams-Diehm (2014) highlighted students are a vital component of the transition planning team. Furthermore, secondary students with disabilities who actively participate in their education and transition planning are more motivated (Skouge, et al., 2007). Student participation in transition planning is just the first step in preparing them for success after high school.

The instruction of self-advocacy skills is another vital component of any student's transition plan. The ability of students to be able to advocate has shown to lead to better post-school outcomes (Wehmeyer \& Palmer, 2003). For this study, self-advocacy means having the support and knowledge to direct one's own life, including articulating strengths, interests, and preferences, in a way that is personally meaningful (Carter et al., 2010). According to Test et al., (2005), there are a variety of components to self-advocacy including knowledge of self, knowledge of rights, communication, and leadership.

\section{Knowledge of Self}

When a student is aware of and able to explain the specific nature and characteristics of his or her disability, and the strengths and weaknesses that exist due to that disability (Berry et al., 2012) reveals increased self-knowledge. However, this awareness of a person's disability does not exist without some reflection. To be knowledgeable about self, true awareness of strengths, needs, interests, preferences, and learning style must exist (Carter et al., 2010). There are a couple of ways to ensure that students obtain a true awareness of their strengths, needs, interests, preferences, and learning styles. First, students should participate in their IEP meeting, which will teach them the accommodations they require as a student but also about their specific IEP goals and services (Gil, 2007; Foley, 2006; Schreiner, 2007). Without this direct participation in their education, students can leave high school without any knowledge 
of their strengths or needs, thus making it difficult to articulate these to future educators or employers. Additionally, according to Hamblet (2014), transition teams should provide students with an understanding of their strengths and weaknesses as a student, and the accommodations needed for success. It is for this reason that knowledge of self is the foundation for college students to be able to self-advocate (Berry et al., 2012).

\section{Knowledge of rights}

The second component of self-advocacy, knowledge of rights, is the ability for a student to "understand his or her rights, responsibilities, and provisions according to the federal legislative guidelines" (Black, 2010, p. 119). While it is important for students to understand their strengths and needs, it is also important for them to know their rights. By the time students with disabilities graduate from high school, they should be able to understand the difference in protections between IDEA, Section 504, and the ADA (Gil, 2007).

\section{Communication}

Communication is another component of self-advocacy. Communication in the self-advocacy framework involves the student effectively communicating his or her needs to others (Kleinert et al., 2010). Many students with disabilities arrive at college unprepared for the shift from others managing their learning to the management of their learning (Hong, Gonzalez, \& Ehrensberger, 2007). According to DaDeppo (2009), "rather than depending on the school system and its representatives to ensure appropriate services and accommodations, an individual with a disability in the postsecondary setting must self-identify as a person with a disability and seek out appropriate accommodations" (p. 123). It is for this purpose that the ability to communicate is a component of the self-advocacy framework.

\section{Leadership}

Lastly, leadership is another vital component of the self-advocacy framework. It is important that individuals show leadership, or go beyond communicating about their own needs to expressing the needs of others as a group of individuals with common concerns (Test et al., 2005). Attendance at IEP meetings is a vital component to learning leadership skills because it is through participation in IEP meetings students will be able to practice leadership skills and group dynamics while still in high school, in anticipation that they will be able to translate these skills once they reach college (Black, 2010).

\section{Self-advocacy framework}

According to Black (2010), the self-advocacy framework is a logical way to break down the necessary skills related to self-advocacy and the method in which to teach these skills. The instruction of these skills is vital to the success of students with disabilities. Students who have self-advocacy skills have better post-school outcomes (Berry et al., 2012). By using the self-advocacy framework to educate students with disabilities on how to advocate for themselves, educators are helping these students experience more success once they leave high school.

Self-advocacy instruction helps individuals identify and challenge environmental and systemic forms of oppression and liberate themselves from oppressive social practices (Ivey \& Collins, 2003). It is through this liberation that students with disabilities can experience success both in school and in postsecondary settings (Astramovich \& Harris, 2007). 


\section{Design of Study}

\section{METHODOLOGY}

This case study explored the amount of self-advocacy instruction students with disabilities received while they were in high school. Selected was a multiple case study design allowing the researchers to "delimit the object of the study, the case" (Merriam, 1998, p. 27) and "study it to achieve as full an understanding of the phenomenon as possible" (p. 28). According to Visnevsky and Beanlands (2004), qualitative research such as this inquiry focuses on human experiences from the perspective of the individual allowing the researchers to examine meaning of transitional planning and self-advocacy in participants' own accounts or meaningful patterns in participants' behaviors (Nelson \& Quintana, 2005). This phenomenological research, examined a teachers and students' first hand experiences (Nelson \& Quinana, 2005; Vishnevsky \& Beanlands, 2004). Therefore, selected to understand the experiences of the participants, was a qualitative case study design for this inquiry

\section{Setting}

Three school districts of differing sizes were chosen based upon their 2014 special education child count data, all located in one Midwestern state. One school site had a special education child count of fewer than 500 students, one had a special education child count between 501 and 1,000 students, and the last school site had a special education child count over 1,000 students. All of these schools offered programs for students in pre-kindergarten through twelfth grade.

Site 1: Valley View School District. The first site for this qualitative case study was a suburban school district, referred to as Valley View School District (pseudonym). The school district located in a community of approximately 8,300 residents, composed of rural areas as well as small neighborhoods. It is primarily a middle-class community where both parents in household work. Their total school population is approximately 2,080 students, which has declined over the past four years from approximately 2,150 students. Valley View School District (pseudonym) serves approximately 220 students through special education services in grades pre-kindergarten through twelfth. The school district has a graduation rate for students with disabilities of $85 \%$, while they show a dropout rate for students with disabilities of $1.5 \%$. Additional data show that $53.8 \%$ of special needs students enroll in higher education after graduation.

Site 2: Washington School District. The second site for this qualitative case study was a suburban school district, referred to as Washington School District (pseudonym). This school district resides in a community of approximately 21,700 residents, comprised of neighborhoods with few families living in a rural setting. Washington School District (pseudonym) serves students in grades pre-kindergarten through twelfth housed in 11 school buildings. The total school population is approximately 4,680, which is a decline from approximately 4,760 four years ago.

Washington School District (pseudonym) serves approximately 650 students with disabilities in grades pre-kindergarten through twelfth. It has a graduation rate for students with disabilities of $78.6 \%$ and a dropout rate for students with disabilities of $1.6 \%$. Additionally, $35.6 \%$ of students with disabilities enroll in higher education.

Site 3: Franklin School District. The final site for this qualitative case study was another suburban school district, referred to as Franklin School District (pseudonym). This school district resides in an area consisting of approximately 95,000 residents, incorporating four different communities into one school district. Comprised of residential areas as well as rural 
areas are these communities. Franklin School District (pseudonym) serves students in grades pre-kindergarten through twelfth housed in twenty-seven school buildings. The school population is approximately 17,700 , which is an increase from approximately 17,500 students four years ago.

Franklin School District (pseudonym) serves approximately 1,560 students with disabilities in grades pre-kindergarten through twelfth. It has a graduation rate for students with disabilities of $81.6 \%$ and a dropout rate for students with disabilities of $1.2 \%$. Approximately 55.7\% of students with disabilities enroll in higher education.

\section{Participants}

Since it is important to select participants from the three sites to illustrate the issue from a variety of perspectives (Creswell, 2015), purposefully chosen were three different groups of participants (Merriam \& Tisdell, 2016). Two of the groups had experience with the transition of students with disabilities, and the third group was disabled students who had graduated from one of these three selected school districts. The first group of participants was Directors of Special Education who had been directors for at least two years and supervised these teachers $(n=3)$. Additionally, they were in districts that offered transition programming for students with disabilities. The second group of participants was special education teachers $(n=15)$ and had experience with transition planning for students with disabilities. Lastly, chosen were college students with documented disabilities $(n=5)$, who had graduated in the last two years from these selected high schools.

\section{Special Education Administrators}

Chosen were special education administrators due to their experiences with the phenomena studied (Merriam \& Tisdell, 2016). These administrators supervised special education programs that enrolled students in K-12 that included transition planning for students with disabilities. These chosen participants had also been special education administrators for at least two years. Since it is important to select participants from different sites to illustrate the issue from a variety of perspectives (Creswell et al., 2007), chosen were three different administrators. One from a school district with a child count of fewer than 500 students, another from a school district with a child count between 501 and 1,000 students, and one from a school district with a child count over 1,000 students. Once a pool of administrators was identified based upon this criteria, the three selected participants were randomly chosen. Additionally, the researcher ensured that there were also teacher participants from the same school district. If special education teachers from a district were unable to participate, the researcher randomly chose an administrator from a different district.

\section{Special Education Teachers}

Due to their direct experiences with the phenomena studied in the research special education teachers participated in this study (Merriam \& Tisdell, 20016). Chosen were fifteen (5 from each of the three sites) special education teachers who had been teaching for at least three years in their respective districts. The teachers all had direct experience with transition planning for students with disabilities and had participated in the IEP meetings of the selected students.

\section{College Students with Disabilities}

College students with disabilities participated in this study because they enabled the researcher to explore a particular aspect of behavior related to the research questions (Merriam \& Tisdell, 2016). These students were between the ages of 18 and 25 and attended a community college. Since community colleges enroll approximately half of all students with 
disabilities seeking higher education (Cashwell, 2014), research student participants attended a community college. Students who had attended one of these school districts and attended a community college within 50 miles of the high school they attended were approached regarding participation in this study. Chosen were five students to participate in this study.

\section{Data Collection}

Within this multi-case study design, director of special education interviews, teacher and student focus groups, allowed the researchers to collect data that would offer, "Detailed views of the participants qualitatively and scores on the instruments quantitatively" (Creswell, 2015 p. 219). Interviews are one of the most important qualitative data collection methods and provide a useful way for researchers to learn about the world of others (Merriam, 2015). The interviews and focus groups within this case study, allowed open, direct, and verbal communication to elicit detailed narratives and stories (Merriam \& Tisdell, 2016) from a total of three different special education administrators.

Following interviews and focus groups, afforded each participant was the opportunity to member-check the transcripts to see if they felt they were a reasonable account of their experiences (Merriam \& Tisdell, 2016). Additionally, the researchers took field notes during the interviews to reflect observations, thoughts, and feelings while collecting data (Merriam, 2015). Triangulation of the data occurred through on-site audio-recorded interviews, which were member checked, and field observations of interactions among focus group participants. By using a case study approach, the researchers were able to analyze the main findings and triangulate from different perspectives.

\section{Data Analysis}

First, open coding was conducted, involving the researchers examining the units of analysis and formulating basic, noninferential descriptions of the phenomena being studied, then grouping them into general categories that described the participants' experiences (Merriam \& Tisdell, 2016). Next, the researchers employed an axial coding method that created inferential descriptions of the processes observed and giving them meaning that was relevant to the research questions. As an additional level of data triangulation (Creswell, 2015), field notes interpreted the findings in the transcriptions.

\section{FINDINGS}

The following themes emerged: 1) Opportunities for Students to Self-Advocate While in High School and 2) The Student Revelation of Self-Advocacy in High School. These themes provide an understanding of opportunities provided to high school students with disabilities that will promote the development of self-advocacy skills from the perspective of district-level administrators, high school teachers, and students with disabilities.

\section{Theme 1: Opportunities for Students to Self-Advocate While in High School}

Wehmeyer and Palmer (2003) found students with high self-determination skills (of which self-advocacy is a sub-skill) during their senior year of high school demonstrated higher levels of financial independence later in life. Data analysis within this study revealed high school special education teachers perceived that they implemented the characteristics of selfadvocacy through their instruction, while the special education administrators noted transitional skills addressed. However, while the special education teachers did express that they implemented instruction in self-advocacy, they acknowledged that this instruction happened in an isolated manner on a case-by-case basis. Additionally, they shared that they did a better job instructing on some of the characteristics than they did with instruction in other areas of self-advocacy. Within this study, school staff offered a variety of opportunities 
through coursework for students to learn self-advocacy skills. Schools offered courses call "transition class" that focused on skills. One teacher said of their transition class, "...they kind of look into all the different options after high school. Then, we work on self-advocacy and learning to be independent..." One District offered a club with a similar focus as the transition class. A teacher describes this, "We had a transition club where she meets with seniors that are going off to college, so they're looking at which college you want to go to, and then we will end up contacting the office of disabilities and making contact for those students."

Although many teachers suggested that there were frequent opportunities to address selfadvocacy instruction through coursework, there were some that acknowledged schools could do a better job. One teacher expressed frustration with the lack of curricular opportunities for students, "We base the IEP off the student, but we do not base the school curriculum always to meet that. It's not all possible to provide them with coursework towards what they want to do." Another teacher expressed similar frustration, "I think we have struggled to find out what is the best transition for each of our kids, based on what we can provide them."

Specific strategies beyond courses noted such as informal conversations with students, helping with self-disclosure, and involving the students in IEP meetings. One teacher stated, 'Those conversations [about self-advocacy] happen almost daily. The kid becomes frustrated because they didn't do well on a test and then they do ask [the] teacher to have it written into [their IEP]." Teachers not only expressed that they were helping students be their advocate while in high school, but also once, they left high school. One teacher stated, "The ones that I know are college bound, we'll talk about how your IEP stops when you walk across the stage, and how 504 is going to take over and we'll explain what that is, and what procedures they'll need to do to get those accommodations in college." Another strategy discussed by the teachers was the issue of students' self-disclosing about their disability once they arrived at college when one highlighted, "We have lessons about self-advocacy that they have to self-identify. I explain there are ways to do that and there are terms that you use."

All of the teachers noted it is important that students participate in their own IEP meetings, teaching them the accommodations they require as a student but also about their specific IEP goals and services. Students also expressed that staff worked with them in the development of their IEP, especially about the accommodations and support needed in classes. One student stated, "We would go through [my IEP], and they would ask me if we needed to change something because it's realistically, primarily pointed to me, to my education. I would say, well, I need more help with this, and then we would fix it so it would help me more on what I needed."

Within the self-advocacy framework, knowledge of self-means that a student is aware of and able to explain the specific nature and characteristics of his or her disability and the strengths and weaknesses that exist due to that disability (Berry et al., 2012). One teacher from the Washington School District acknowledged that students are not knowledgeable about their disability, "There are others that have no idea what their disability is, don't want to talk about it." Another teacher from the same school district acknowledged a few students could discuss their disability, "I have a couple of students who can talk about their disability, who understand their disability, and I think those conversations with those students start at home." On the other hand, one teacher from the Valley View School District acknowledged a good job done at school to teach students about their disability, "I'm pretty open with my students in the sense that this is where you're functioning at, these are the things that are going on." 
Another component of self-advocacy, knowledge of rights, is the ability for a student to "understand his or her rights, responsibilities, and provisions according to the federal legislative guidelines" (Black, 2010, p. 119). Special education teachers acknowledged that they visit with students about the laws that govern the provision of services to people with disabilities on a case-by-case basis, "For me, it was something, based on that student's situation, and when something you know, comes up for them to have those specific conversations," said a teacher from the Washington School District. On the other hand, staff suggested a slight emphasis on teaching students about laws for people with disabilities. When asked how much instruction students received, one teacher from the Valley View School District replied, "Very little." While another teacher from the Franklin district said, "We don't do anything as a group. Our case managers talk to them at IEP meetings and tell them why."

Communication is another component of self-advocacy. Communication within the selfadvocacy framework involves the student being able to communicate his or her needs to others (Kleinert et al., 2010). Again, teachers acknowledged that instruction in the component of communication within the self-advocacy framework is done on a case-by-case basis. One teacher from the Valley View School District said, "I'm trying to teach them to respond instead of me to respond because I want them to get ready for that in the real world." A teacher from the Washington School District said we are teaching students to communicate by "...helping them solve their problems by communicating and remaining calm and being respectful."

Lastly, leadership within the self-advocacy framework involves the student going beyond merely communicating about his or her own needs to expressing the needs of others as a group of individuals with common characteristics (Test et al., 2005). Leadership is an area not addressed often by staff, although the Franklin School District Administrator acknowledged the importance, "If you can advocate for yourself and others that is going to be a high predictor for leadership." In addition, the administrator from Washington, highlighted, "We try to teach all students to be leaders."

Based on the responses gathered during this research, the characteristics of self-advocacy implemented within the school system was on a one-on-one basis rather than as a whole group implementation contrary to the importance that the literature noted regarding self-advocacy. The ability of students to self-advocate is vital for success later in life and students with high self-determination skills during their senior year of high school demonstrated higher levels of financial independence later in life (Wehmeyer \& Palmer, 2003). This ability to self-advocate is necessary for many students and should be a part of every student's transition plan while in high school (Janiga \& Costenbader, 2002).

\section{Theme 2: The Student Revelation of Self-Advocacy in High School}

While administrators and teachers shared they were addressing self-advocacy on a case-bycase basis; students felt that they needed direct instruction about how to handle specific situations related to self-advocacy. The instruction that college students received while in high school about knowledge of self, or the awareness and ability to explain the specific nature and characteristics of their disability and the strengths and weaknesses associated with it (Berry et al., 2012; Black, 2010) was limited to specific events of their high school career. Specifically, a self-advocacy skill missing was self-awareness. The instruction students received while in high school about knowledge of self, or the awareness and ability to explain the specific nature of their disability was limited. One student said, "The only time we got to talk about our learning disability was when we were in our IEP meetings." Another student said that he would "...get excited when it comes to my IEP because I want to show that I'm an individual and I' $m$ an advocate for myself..." When asked another student noted he had no conversations about his 
disability, he responded, "Probably with my mom I did." While these statements were about disability, students expressed the same concerns about self-advocacy instruction. Students shared that they on their own, or must work through their families, to learn how to selfadvocate.

Overall, students interviewed did not conclude that schools prepared them with the knowledge of rights they needed. One student said that he "Basically...taught me those laws." When asked what schools could do to prepare students with disabilities for college he responded, "Tell us more about the laws...what we're allowed to have outside of our IEP when we leave for college..." Students acknowledged the need for this instruction, however, researched it on their own because they did not get instruction in the laws governing people with disabilities while in high school.

According to many students, this instruction often came from family members rather than school staff. Explicitly, an area that all students felt was lacking was instruction in legal rights for people with disabilities. While a few had direct instruction about laws as students, this is an area not often taught, leaving students to find answers through their research. As one student stated, "When it came to my rights I did not understand them, so I googled and got an answer." Another student said, "Basically I taught myself those laws."

About their IEP, students acknowledged they had opportunities to communicate their needs. One student said, "We would go through it, and they would ask me if we needed to change something because it's realistically primarily pointed at me, to my education. I would say, well, I need more help with this, and then we would fix it so it would help me more on what I needed help to do."

Another student relied on his mother to help him prepare communications, "If we needed a new accommodation, [mom] would talk to us about it. Okay, you need to tell this..." However, one student expressed that she got "excited when it comes to my IEP because I want to show that I'm an individual and I'm an advocate for myself and I wanted to say what I need..."

The last characteristic of self-advocacy, leadership, refers to the ability to be able to express the needs of others as a group of individuals with common concerns (Test et al., 2005). One student reported the desire to work with other students with disabilities to fight for their needs. She said, "I know if we stick together it will help." Students expressed some opportunities to show leadership, however many of these did not involve advocacy for students with disabilities. One student reported that he was a student representative to his city council. Moreover, two students noted opportunities they had to express the needs of students with disabilities to a group. One student "...did an essay about disabilities... and did a little [speech] in that language arts class." Another student reported that she had conversations with other students with disabilities about extracurricular activities that worked well with students with special needs. Nevertheless, both students felt that leadership skill came from support at home rather than with teachers guiding them.

Thus, perceptions of college students with disabilities regarding their instruction on the characteristics of self-advocacy varied depending on the characteristic. Students expressed they had some level of knowledge about their needs about their disability. They also expressed they had the opportunity to communicate the needs associated with their disability, which is important as the shift from someone else managing their education to managing it themselves occurs (Hong et al., 2007). Conversely, they did not know the rights afforded to people with disabilities and did not have the opportunity to develop leadership skills, both of which are 
important characteristics of self-advocacy, and should be a component in the education of high school students with disabilities (Janiga \& Costenbader, 2002). Therefore, while there was consensus on the importance of self-advocacy instruction from both teachers and administrators, there were differing opinions about how students achieved this.

\section{DISCUSSION}

A plan for transitioning to post-school activities is essential to ensuring success for students transitioning from high school. All of the educators in this study understood that a transition plan is required under IDEA and involved a coordinated set of activities based on a student's needs, preferences, and interests (Wagner, Newman, Cameto, Javitz, \& Valdes, 2012). However, the findings differed from Hurwitz (2008) who identified such activities to include instruction, community services, and the development of postsecondary training preparing students for life after high school. Overall, the findings revealed while high school special education teachers perceived that while they implemented the components of self-advocacy, it happened in an isolated manner on a case-by-case basis. Because these activities should be outcome-oriented (Rehfeldt, Clark, \& Lee, 2012) and promote movement from high school to postsecondary, it is essential that instead of a piecemeal approach, a systematic, comprehensive approach is necessary. Addressed within this transition plan should be the wide variety of needs that a student is going to face, including self-advocacy skills (Smith et al,, 2002). These educators recognized the need for transition plans, but their approach to teaching self-advocacy skills ranged from a course in one school setting to talking to the student during the IEP meeting or meeting one to one with students.

Within the self-advocacy framework, the awareness of one's disability and the ability to identify and explain the characteristics of one's disability (Berry et al., 2012; Black, 2010; Sebag, 2010) is essential. However, in this investigation, the accomplishment of this was inconsistent as illustrated by the teachers, and the students reported this skill practiced mostly during IEP meetings. Since students with learning disabilities are their advocates on college campuses, it is imperative that students with disabilities be able to disclose their disability as well as practice self-advocacy skills (Gil, 2007; Foley, 2006). Subsequently, while researchers have denoted the value of self-awareness of disabilities for high school students (Gil, 2007; Foley, 2006; Schriener, 2007), instruction of self-advocacy skills is not consistently being done in all high school settings.

Even though it is important for students to understand their strengths and needs, it is also important for them to know their rights.

Another component of self-advocacy, the knowledge of rights, acknowledged by Black (2010) as the ability for a student to "understand his or her rights, responsibilities, and provisions according to the federal legislative guidelines" (p. 119), was also viewed by the students as inconsistently taught. A few students indicated during IEP meetings, discussion of their rights occurred, more often than not, the students reported that they had "googled" their rights or their parents had discussed them with them. While the educators in this study agreed by the time students with disabilities graduate from high school, they should be able to understand the difference in protections between IDEA, Section 504, and the ADA (Eckes \& Ochoa, 2005; Gil, 2007), their approach was not as systematic as they wanted. Educators agreed before leaving high school; staff should articulate the differences in the laws and ensure that students understand.

Although it is essential for a student to understand his or her strengths and needs, as well as rights provided through federal laws, it is also important that the student be able to 
communicate their needs. Again, teachers acknowledged that instruction in the component of communication within the self-advocacy framework was on a case-by-case basis. Consequently, without this communication skill, students will not consistently communicate to postsecondary staff their individual needs. Being able to communicate their strengths and needs is a step toward taking ownership of their learning. These findings aligned with Hong, Gonzalelz, and Ehrensberger (2007), whereby many of these students arrived at college unprepared for the shift from others supervising their learning to the management of their learning. On a positive note, this research found that many of these students, while not receiving direct instruction on communication were able to seek out appropriate accommodations.

Finally, leadership is another vital component of the self-advocacy framework. Moreover, it is important that students show leadership or go beyond communicating about his or her own needs to expressing the needs of others as a group of individuals with common concerns (Pennell, 2001; Test et al., 2005). These findings revealed that these students did attend IEP meetings, and many noted this participation allowed them to learn leadership skills. In addition, a few of these students noted that they had expressed the needs of other disabled students through community work. Incorporating a focus on leadership skills within the transition planning could further advance this self-advocacy skill.

\section{CONCLUSIONS}

This qualitative case study examined the level of self-advocacy instruction high school students with disabilities received. Educators denoted self-advocacy to be a valuable skill; however, the students revealed a lack of opportunities to self-advocate during transitional planning. Administrators and teachers felt they had provided opportunities, while conversely, students felt they had to do things on their own or through their parents. Although students and educators both expressed that students' level of involvement in IEP meetings was high and gave students the opportunity to self-advocate regarding courses and accommodations, noted within that context were little to no discussion of their disability or their rights. As a result, the findings of this study identified a need for schools to offer additional opportunities for students with disabilities to learn about their legal rights and to self-advocate for those rights. Additionally, there is a need for students with disabilities to have the opportunity to learn about their disability and be able to express the needs associated with a disability and provided opportunities to be leaders in this advocacy. While self-advocacy is a multidimensional construct, it is vital to the success of students with disabilities and is essential in transitional planning.

\section{IMPLICATIONS}

The findings indicate self-advocacy instruction for high school students with disabilities occurs primarily on a situational basis. However, it is important that teachers provide students training in how to self-advocate. To do this, teachers need training in how to prepare effectively transitional plans for all students using a self-advocacy model. This preparation should occur during teachers' preservice, in addition to their post-professional learning training.

Teachers also need training in how to enhance instruction about the rights students are afforded as individuals with disabilities. Additionally, students with disabilities need practice and support in expressing the nature of their disability and the needs associated with the disability. High school leadership further needs to support students' efforts by allowing them the opportunity to self-advocate within the school setting and holding staff accountable for meeting the accommodations. 
This study similarly has implications for practice for post-secondary institutions. Since the provision of accommodations is a mandated activity, post-secondary institutions should evaluate how they are disseminating information to students and staff. As well, it is necessary that post-secondary instructors and staff know how to access information regarding students with disabilities, identify, and design accommodations for their specific course. Training for post-secondary instructors is necessary if all students are to achieve positive learning outcomes in higher education institutions. By using the self-advocacy framework to educate students with disabilities on how to advocate for themselves, educators are helping these students experience more success once they leave high school and enter into a post-secondary environment.

\section{References}

Astramovich, R.L., \& Harris, K.R. (2007). Promoting self-advocacy among minority students In school counseling. Journal of Counseling and Development, 85, 269-276.

Berry, H.G., Ward, M., Caplan, L. (2012). Self-determination and access to postsecondary education in transitioning youths receiving supplemental security income benefits. Career Development and Transition for Exceptional Individuals, 35, 68-75.

Black, J. (2010). Digital transition portfolios for secondary students with disabilities. Intervention in School and Clinic, 46, 118-124. doi:10.1177/1053451210374987

Carter, E.W., Trainor, A., Owens, L., Sweden, B., \& Sun, Y. (2010). Self-determination prospects of youth with highincidence disabilities: Divergent perspectives and related factors. Journal of Emotional and Behavioral Disorders, $18,67-81$.

Creswell, J. (2015). Research Design qualitative, quantitative, and mixed methods approaches. Thousand Oaks, CA: SAGE Publications.

DaDeppo, L. M. (2009). Integration factors related to the academic success and intent to persist of college students with learning disabilities. Learning Disabilities Research \& Practice, 24, 122-131.

DiCicco-Bloom, B., \& Crabtree, B.F. (2006). The qualitative research interview. Medical Education, 40, 314-321.

Foley, N. E. (2006). Preparing for college: Improving the odds for students with learning disabilities. College Student Journal, 40, 641-645.

Gil, L. A. (2007). Bridging the transition gap from high school to college: Preparing students with disabilities for a successful post-secondary experience. Teaching Exceptional Children, 40, 12-15.

Gregg, N. (2009). Adolescents and adults with learning disabilities and ADHD: Assessment and accommodation. New York: Guilford.

Hamblet, E.C. (2014). Nine strategies to improve college transition planning for students with disabilities. Teaching Exceptional Children, 46, 53-59.

Hetherington, S.A., Durant-Jones, L., Johnson, K., Nolan, K., Smith, E., Taylor-Brown, S., \& Tuttle, J. (2010). The lived experiences of adolescents with disabilities and their parents in transition planning. Focus on Autism and Other Developmental Disabilities, 25, 163-172.

Hong, B.S., Ivy, W.F., Gonzalez, H.R., \& Ehrensberger, W. (2007). Preparing students for postsecondary education. Teaching Exceptional Children, 40, 32-38.

Hurwitz, K. A. (2008). A review of special education law. Pediatric Neurology, 39, 147-154.

Ivey, A.E., \& Collins, N.M. (2003). Social justice: A long-term challenge for counseling psychology. The Counseling Psychologist, 31, 290-298.

Janiga, S.J., \& Costenbader, V. (2002). The transition from high school to postsecondary education for students with learning disabilities: A survey of college service coordinators. Journal of Learning Disabilities, 35, 462-468.

doi:10.1177/00222194020350050601

Karvonen, M., Test, D.W., Wood, W.M., Browder, D., \& Algozzine, B. (2004). Putting self-determination into practice. Exceptional Children, 71, 23-41. 
Kleinert, J.O., Harrison, E.M., Fisher, T.L., \& Kleinert, H.L. (2010). “I can” and "I did" - self-advocacy for young students with developmental disabilities. Teaching Exceptional Children, 43, 16-26.

Merriam, S.B. (1998). Qualitative research and case study applications in education. San Francisco, CA: Jossey-Bass.

Merriam, S. B., \& Tisdell, E. J. (2016). Qualitative research: A guide to design and implementation (4th ed.). San Francisco, CA: Jossey-Bass.

Morningstar, M.E., \& Liss, J.M. (2008). A preliminary investigation of how states are responding to the transition assessment requirements under IDEA 2004. CareerDevelopment for Exceptional Individuals, 31, 48-55.

Nelson, M.L., \& Quintana, S.M. (2005). Qualitative clinical research with children and adolescents. Journal of Clinical and Adolescent Psychology, 34, 344-356.

Sanford, C., Newman, L., Wagner, M., Cameto, R., Knokey, A-M., \& Shaver, D. (2011). The post-high school outcomes of young adults with disabilities up to 6 years after high school. Key findings from the national longitudinal transition study-2 (NLTS2). Menlo Park, CA: SRI International.

Schreiner, M.B., (2007). Effective self-advocacy: What students and special educators need to know. Intervention in School and Clinic, 42, 300-304.

Skouge, J., Kelly, M., Roberts, K., Leake, D., \& Stodden, R. (2007). Technologies for self-determination for youth with developmental disabilities. Education and Training In Developmental Disabilities, 42, 475-482.

Smith, S. G., English, R., \&Vasek, D. (2002). Student and Parent Involvement in the transition Process for College Freshmen with Learning Disabilities. College Student Journal, 36(4), 491+. Retrieved from http://www.questia.com

Test, D.W., Fowler, C.H., Wood, W.M., Brewer, D.M., \& Eddy, S. (2005). A conceptual framework of self-advocacy for students with disabilities. Remedial and Special Education, 26, 43-54. doi:10.1177/07419325050260010601

Wagner, M., Newman, L., Cameto, R., Javitz, H., \& Valdes, K. (2012). A national picture of parent and youth participation in IEP and transition planning meetings. Journal of Disability Policy Studies, 23, 140-155.

Wehmeyer, M., \& Palmer, S. (2003). Adult outcomes for students with cognitive disabilities three-years after high school: The impact of self-determination. Education and Training in Developmental Disabilities, 38, $131-144$.

Vishnevsky, T., \& Beanlands, H. (2004). Qualitative research. Nephrology Nursing Journal, 31, 234-238.

Williams-Diehm, K.L., Brandes, J.A., Chesnut, P.W., \& Haring, K.A. (2014). Student and parent IEP collaboration: A comparison across school settings. Rural Special Education Quarterly, 33, 3-11. 